\title{
Injury and inflammation in the eye
}

\author{
P. BhatTACHERJEe \\ M.Sc., Ph.D.
}

D. F. COLE

B.Sc., Ph.D.

Institute of Ophthalmology, London WCI

THE rabbit eye has been used extensively as an experimental model to investigate the effects of injury and inflammation and the present paper summarizes some of the recent work on the role of prostaglandins in the two types of response.

Injury, the acute response to chemical, mechanical, or thermal insults to the eye or its contents, typically produces on increase of intra-ocular pressure (ocular hypertension), breakdown of the bloodaqueous barrier with leakage of plasma protein into the aqueous humour and intense miosis (Davson, 1956). The ocular hypertension commences immediately and subsides within one hour but the increased permeability of the barrier may persist for several days. This type of response can be simulated by intracameral or topical administration of $E_{1}$ or $E_{2}$ prostaglandin (Waitzman and King, 1967; Beitch and Eakins, 1969) and may be wholly or partially inhibited by polyphloretin phosphate, a compound showing anti-prostaglandin activity, or by pre-treatment with indomethacin (Bethel and Eakins, 1972; Cole and Unger, 1973; Perkins, Unger and Bass, 1973; Cole, 1974). Following certain types of injury, prostaglandin-like material may be detected in the aqueous humour (Ambache, Kavanagh and Whiting, 1965) but in other instances, such as antidromic stimulation of the fifth nerve, an apparently typical injury response may be induced which is not accompanied by liberation of prostaglandin-like material and is not blocked by indomethacin (Cole and Unger, 1973).

It has been suggested that two pathways are concerned in the injury response; one mediated via production of $E_{2}$-prostaglandin by the iris tissue and another dependent on an intact sensory nerve supply. This is exemplified in the case of ruby-laser injury to the iris. The ocular hypertension resulting from this type of trauma is partially inhibited either by pre-treatment with indomethacin or by topical treatment with local anaesthetics and is almost completely abolished by both treatments given together (Unger, Cole and Bass, 1977).

The rabbit eye may also be used as an experimental model for anterior uveitis, intra-ocular inflammation affecting the anterior part of the uv ea tract. This can be produced by intra-vitreal injection of bovine serum of albumin (BSA) or Shigella endotoxin (Zimmerman and Silverstein, 1959; Eakins et al., 1973; Bito, 1974; Whitelocke, 1975). BSA-uveitis is an immunogenic response reaching a maximum 8-12 days after the original injection and is associated with iris vasodilatation, transient ocular hypertension and breakdown of the bloodaqueous barrier with an increase of protein concentration and leucocytes in the anterior chamber. In the case of endotoxin-uveitis the events are similar but the onset is more rapid and the response less protracted (Bito, 1974). In both cases there is an increase in the level of prostaglandin-like substances in the aqueous humour, predominantly a mixture of $E_{1}$ and $E_{2}$ types, the $E_{1}$-prostaglandins possibly arising from the leucocyte infiltration (Eakins et al.; 1972b; Eakins et al., 1972a; Bhattacherjee, 1975). A similar increase in the level of prostaglandin-like substances has been reported by Bhattacherjee, Rahi and Misra (1977) in the aqueous humour of rabbits with immune complex endophthalmitis (Type III allergy). This is produced when animals are immunized with human serum or homologous/ autologous lens homogenate and subsequently challenged by intravitreal injection of the antigen. Although prostaglandin-like substances are obviously important in both types of uveitis it is possible to inhibit the prostaglandin synthetase system with indomethacin without completely abolishing the inflammatory response and migration of leucocytes across the blood-aqueous barrier (Bhattacherjee, 1975).

The increase in the level of prostaglandin-like substances in the aqueous can be ascribed to two factors. Firstly, there is increased tissue synthesis and, while this appears to be due partly to increased substrate levels, there is also, in the case of endotoxin-uveitis, evidence for an increase in the activity of the prostaglandin synthetase system itself (Bhattacherjee, 1977). Secondly, there is a fall in the rate at which prostaglandin-like substances are removed from the aqueous humour. Bito and Salvador (1972) 
have shown that prostaglandins can be actively transported out of the eye across the ciliary epithelium, and Bito $(1973,1974)$ has demonstrated a failure of this mechanism in BSA- and endotoxinuveitis. The ocular tissues themselves have comparatively little prostaglandin dehydrogenase activity in vitro (Eakins, Atwal and Bhattacherjee, 1974) and the failure of the 'transport-out' system would seem to be an important feature in the pathogenesis of uveitis since this will render the anterior segment of the eye more susceptible to recurrence of the condition.

\section{Acknowledgment}

This work was supported in part by a grant from the Medical Research Council.

\section{References}

Ambache, N., Kavanagh, L. \& Whiting, J. (1965) Effect of mechanical stimulation on rabbits' eyes: release of active substances in anterior chamber perfusates. Journal of Physiology. London, 176, 378.

BeITCH, B.R. \& EAKINS, K.E. (1969) The effects of prostaglandins on the intraocular pressure of the rabbit. British Journal of Pharmacology, 37, 158.

Bethal, R.A. \& Eakins, K.E. (1972) The mechanism of the antagonism of experimentally induced ocular hypertension by polyphloretin phosphate. Experimental Eye Research, 13, 83.

BHATTACHERJEe, P. (1975) Release of prostaglandin-like substances by Shigella endotoxin and its inhibition by non-steroidal anti-inflammatory compounds. British Journal of Pharmacology, 54, 489.

BhatTACHERJEe, P. (1977) Stimulation of prostaglandin synthetase activity in inflamed ocular tissue of the rabbit. Experimental Eye Research, 24, 215.

Bito, L.Z. (1973) Inhibition of uveal prostaglandin transport in experimental uveitis. In: Prostaglandins and Cyclic AMP (Ed. by R. H. Kahn and W. E. M. Lands), pp. 213-214. Academic Press, New York.

Bito, Z.L. (1974) The effects of experimental uveitis on anterior uveal prostaglandin transport and aqueous humor composition. Investigative Ophthalmology, 13, 959.
Bito, L.Z. \& Salvador, E.V. (1972) Intraocular fluid dynamics. III. The site and mechanism of prostaglandin transfer across the blood intraocular fluid barriers. Experimental Eye Research, 14, 233.

ColE, D.F. (1974) Formaldehyde-induced ocular hypertension: the effects of polyphloretin phosphate and $(+)-$ Catechin. Experimental Eye Research, 19, 533.

Cole, D.F. \& Unger, W.G. (1973) Prostaglandins as mediators for the responses of the eye to trauma. Experimental Eye Research, 17, 357-368.

Davson, H. (1956) Physiology of the ocular and cerebrospinal fluids. J. and A. Churchill. London.

Eakins, K.E., Atwal, M. \& BhatTacherjee, P. (1974) Inactivation of prostaglandin $\mathrm{E}_{1}$ by ocular tissues in vitro. Experimental Eve Research, 19, 141.

Eakins, K.E., Whitelocke, R.A.F., Bennett, A. \& MarTENET, A.C. (1972a) Prostaglandin-like activity in ocular inflammation. British Medical Journal, 3, 452.

Eakins, K.E., Whitelocke, R.A.F., Perkins, E.S., Bennett, A. \& UNGER, W.G. (1972b) Release of prostaglandins in ocular inflammation in the rabbit. Nature, New Biology, 239, 248.

Eakins, K.E., Whitelocke, R.A.F., Perkins, E.S., Bennett, A. \& UNGer, W.G. (1973) Prostaglandin release in ocular inflammation in rabbits and man. In: Advances in Biosciences (Ed. by S. Bergstrom and S. Bernhard), 9, 427. Pergamon Press, Oxford.

Perkins, E.S., UNGer, W.G. \& Bass, M.S. (1973) The role of prostaglandin in the ocular response to laser irradiation of the iris. Experimental Eye Research, 17, 394.

RAHI, A.H.S., BhatTACHERJEe, P. \& MisRa, B.N. (1977) Release of prostaglandins in experimental immune complex endophthalmitis and phacoallergic uveitis. British Journal of Ophthalmology (in press).

Unger, W.G., Cole, D.F. \& Bass, M.S. (1977) Prostaglandin and neurogenically mediated ocular response to laser irradiation of the rabbit lens. Experimental Eye Research (in press).

Waitzman, M.B. \& KING, C.D. (1967) Prostaglandin influences on intra-ocular pressure and pupil size. American Journal of Physiology, 212, 329.

Whitelocke, R.A.F. (1975) Prostaglandins in ocular inflammation. Ph.D. Thesis, University of London.

Zimmerman, L.E. \& Silverstein, A.M. (1959) Experimental ocular hypersensitivity: histopathologic changes observed in rabbits receiving a single injection of antigen into the vitreous. American Journal of Ophthalmology, 48, 447. 